\title{
MIIASIS HUMANA: CASO CLÍNICO
}

\section{ARTÍCULO ORIGINAL}

SILVA, Agnaldo Plácido da ${ }^{1}$, PLÁCIDO, Eloá Jessica Mendes dos Santos², MORAES, Walber Breno de Souza ${ }^{3}$

SILVA, Agnaldo Plácido da. PLÁCIDO, Eloá Jessica Mendes dos Santos. MORAES, Walber Breno de Souza. Miiasis humana: Caso clínico. Revista Científica Multidisciplinar Núcleo do Conhecimento. Año 05, Ed. 08, Vol. 10, págs. 39-46. Agosto de 2020. ISSN: 2448-0959, Enlace de acceso: https://www.nucleodoconhecimento.com.br/saude/miiase-humana, DOI: 10.32749/nucleodoconhecimento.com.br/salud/miiasis-humana

\section{RESUMEN}

La miiasis se considera una infestación por dermatozoonosis causada por la infestación de larvas dipteranas en tejidos u órganos, que ponen sus óvulos en humanos o animales, que durante un cierto período se alimentan de tejidos vivos o muertos del huésped la aparición de miiasis en la cavidad oral puede considerarse algo raro. Este tipo de enfermedad afecta con mayor frecuencia a personas de bajo nivel socioeconómico, inmunocomprometidos, ancianos postrados en cama y con trastornos psiquiátricos. Debido a su gran potencial destructivo, una prevención y tratamiento oportuno e importante adecuado, también hay poco conocimiento del profesional dental para el diagnóstico y tratamiento de dicha patología, por esta razón, el presente estudio informa de un caso clínico de miiasis oral en una persona de edad avanzada postrada en cama con antecedentes de lesión de neoplasia laríngea/glotal maligna, presentando debilidad física y mental y falta inadecuada de

\footnotetext{
${ }^{1}$ Estudiante de doctorado en Ciencias Biomédicas en IUNIR - Instituto Universitario Italiano de Rosario Argentina. Especialista en Cirugía Bucomaxilofacial y Traumatología por Ciodonto - Clínica Integrada de Odontología. Licenciado en Odontología por ASCES - Asociación Caruaruense de Educación Superior. Licenciado en Bióloga por la UPE - Universidad de Pernambuco.

${ }^{2}$ Graduado del Curso de Fisioterapia del Colegio UNINASSAU.

${ }^{3}$ Licenciado en Biología UPE- Universidad de Pernambuco. Máster en Recursos Naturales - UFCG. Profesor de la UNOPAR.
} 
seno de la lengua. El diagnóstico se estableció clínicamente sobre la base de la observación del sangrado de la lengua, el desprendimiento de tejidos y la presencia de larvas que se encontraban entre la segunda y tercera etapas de desarrollo. El tratamiento se inició como hospitalización del paciente para la desbridación de tejidos necróticos y la eliminación de larvas y prescripción de ivermectina. Los pacientes postrados en cama con debilidad física y metálica constituyen un grupo de riesgo para la miiasis oral, y es de gran importancia guiar a los cuidadores y familiares en relación con el cuidado dental con el fin de prevenir esta patología. Sin embargo, la falta de consenso sobre el mejor enfoque terapéutico para los casos de miiasis oral se tomó como conducta terapéutica para la enfermedad la eliminación mecánica de larvas y la institución de uso oral de ivermectina.

Palabras clave: Larva, miiasis humana, moscas, salud pública.

\section{INTRODUCCIÓN}

La miiasis se define como una patología en la que hay pestilencia de larvas de moscas que se alimentan de tejidos vivos o muertos (VINIT; JAYAVELU y SHRUTHA, 2013), aunque esta parasitosis ha sido descrita durante muchos años por los investigadores, el término técnico para designar la bicheira fue sugerido en 1840 por el Reverendo F. W. Hope en su trabajo "On insects and their larvae occasionally found in the human body", que se deriva de las palabras griegas myia (mosca) y ase (enfermedad) (GUIMARAES; PAPAVERO y PRADO, 1983). En la literatura hindú la miiasis era considerada por la mitología como un castigo a los pecadores (PARMAR; DAVESSAR et al., 2018).

Los pacientes con miiasis generalmente presentan algunos factores que conducen a la predisposición a su desarrollo, como retraso mental, trastornos psiquiátricos, senilidad, enfermedades vasculares, neoplasias, diabetes e inmunodepresión y consumo crónico de alcohol, y ocurre preferentemente en los ancianos. (MARQUEZ; MATTOS y NASCIMENTO, 2007) (SILVEIRA; PINHEIRO et al., 2015) Sin embargo, los factores de mayor relevancia para la aparición de la miiasis siguen siendo la 
aparición de lesiones expuestas con exudaciones y mala higiene corporal y oral (NASCIMENTO; OLIVEIRA et al., 2005) (TOURÉ, 1994).

Esta es una situación de gravedad fatal para el paciente, además de causar dolor y destrucción tisular. La miiasis oral puede presentarse como laceración de la cavidad oral, hinchazón de la mucosa oral, inflamación del gingival (RIBEIRO; PEREIRA et al., 2001). "En el caso de la Myiasis cavitaria, que comprende las regiones de la boca y la nariz y el seno paranasal, se puede afirmar que es un tipo muy raro de miiasis" (BARNA-C; FERRAZ et al., 2016). La variedad más frecuente de especies de mosca responsables de la mayoría de los casos de miiasis incluye Cochliomyia hominivorax, Chrysomya bezziana, Oestrus ovis, magnífica Wohlfahrtia y la Musca doméstica. La incidencia de la infección es poco frecuente incluso en los países en desarrollo (KHAN; SABIR et al., 2018) (TOURÉ, 1994).

El tratamiento de la miasis consiste básicamente en la extracción manual de las larvas, con la ayuda de una cureta y pinzas clínicas, generalmente bajo anestesia o analgesia, dependiendo del estado clínico del paciente, la extracción de las larvas se debe hacer con cuidado, de modo que el las larvas no están fragmentadas y sus restos permanecen en su lugar generando un proceso infeccioso (CAVALCANTI, 2008), aunque existen algunos productos en el mercado que pueden utilizarse para facilitar la remoción (BARNABÉ; FERRAZ et al., 2016), la literatura informa con gran éxito el uso sistémico de una dosis de ivermectina, un antibiótico macrólido semisintético para el tratamiento de casos más graves que implican la existencia de miasis oral, demostrando ser un método seguro a las dosis recomendadas de 200 $\mu \mathrm{g} / \mathrm{kg}$. Incluso a dosis de $300 \circ 400 \mu \mathrm{g} / \mathrm{kg}$, los pacientes en tratamiento no presentaron ningún efecto secundario clínico importante, salvo prurito leve (GEALH; FERREIRA et al., 2009) (RIBEIRO; PEREIRA et al., 2001).

Podemos clasificar la Miiasis en tres tipos diferentes: biontofagosos o primarios que son aquellas larvas dipteranas que se desarrollan en o dentro de vertebrados, alimentándose de los tejidos del huésped vivo. Entre estas especies, podemos encontrar Cochliomy homini vorax y Dermatobia hominis. Los necrobiollinos 
secundarios son aquellos en los que las larvas dipteranas se convierten en materia orgánica que ya es descomposición (cadavélis), actuando como saprofago, pero también puede afectar a los tejidos necróticos en un huésped vivo. Los géneros más comunes son: Lucília, Phaenicia, Musca y Fannia. Pseudomiiasis (accidental): esto puede ocurrir por ingestión de óvulos y/o larvas dipteranas presentes en alimentos contaminados ingeridos por el huésped, causando un trastorno intestinal (CAVALCANTI, 2008) (BOROS; BOROS et al., 2006).

\section{CASO CLÍNICO}

Un paciente varón de 69 años diagnosticado con neoplasia maligna en la lengua (sometido a quimioterapia) fue ingresado en la sala de urgencias del Hospital Regional Dom Moura en Garanhuns - Pernambuco quejándose de dolor e infrecuente en la región bucal durante varias semanas, fue referido al servicio de Cirugía Bucomaxillofacial y Traumatología. Al ingresar, el paciente era afebrile, orientado y cooperativo, se observó sangrado en la boca, teniendo en cuenta el informe de la familia de que el paciente tenía problemas dentales, y se realizaron exámenes. En la evaluación intraoral mostró una lesión ulcerosa bien definida con tejido necrótico central y varias larvas vivas en la lengua. (Figura 1) 
Figura 1 - Larvas en la lengua.

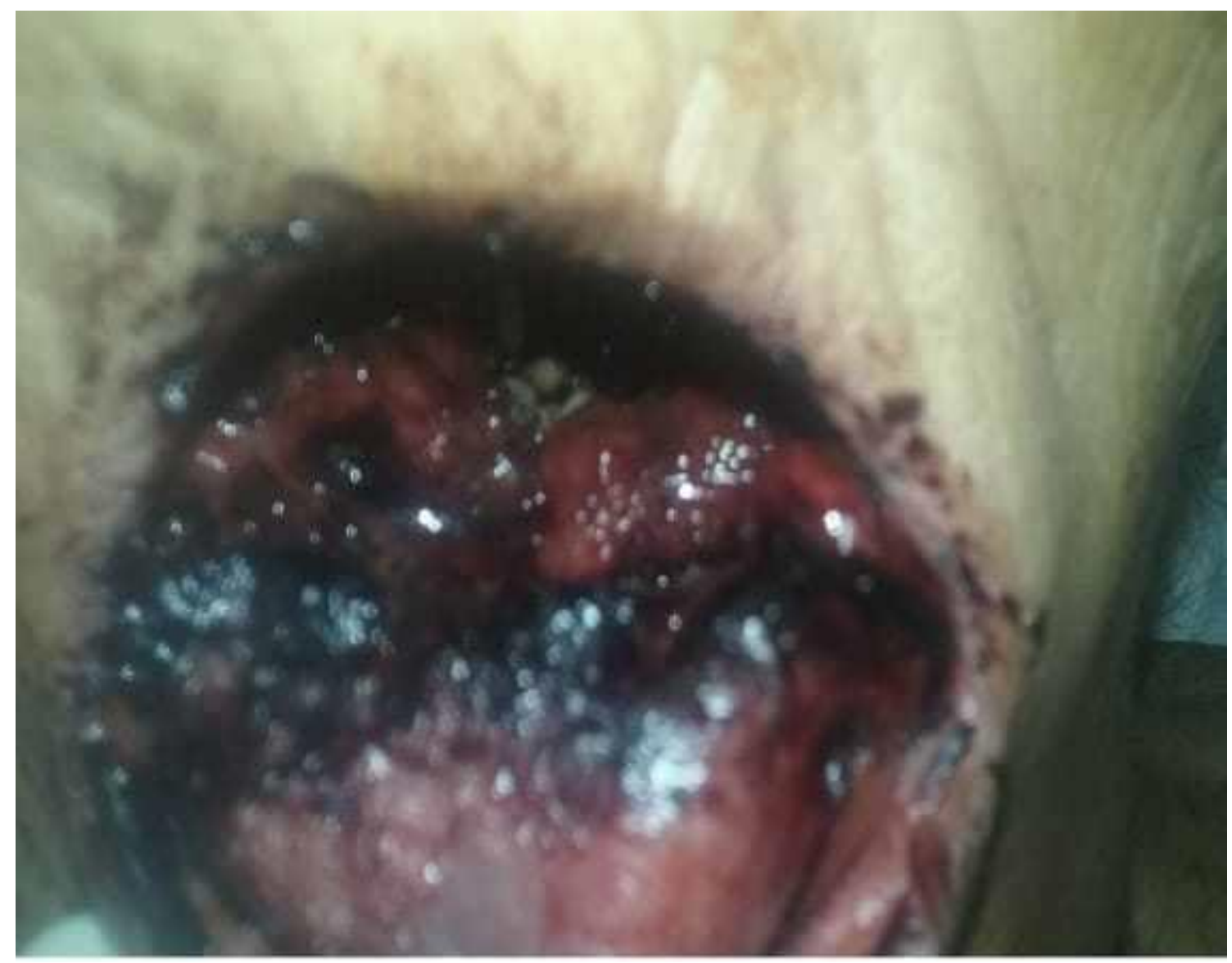

Fuente: Los autores (2020).

El paciente afectado por la enfermedad presentó factores predisponentes como debilidad física y mental, deshidratación, higiene corporal inadecuada, diabetes, desnutrición, respiración bucal durante el sueño y mal mantenimiento de la higiene bucal.

Por lo tanto, se realizó el tratamiento sintomático primario. La herida se limpió y desinfectó con una solución de clorhexidina al $0,12 \%$. Las larvas fueron retiradas manualmente bajo anestesia local con la ayuda de pinzas clínicas, todo el campo aséptico, las larvas en este caso fueron recogidas y colocadas en una bandeja clínica. Aproximadamente 80 larvas fueron retiradas de la región, y todas ellas no pudieron ser removidas (Figura 2). 
Figura 2 - Larvas extraídas de la lesión.

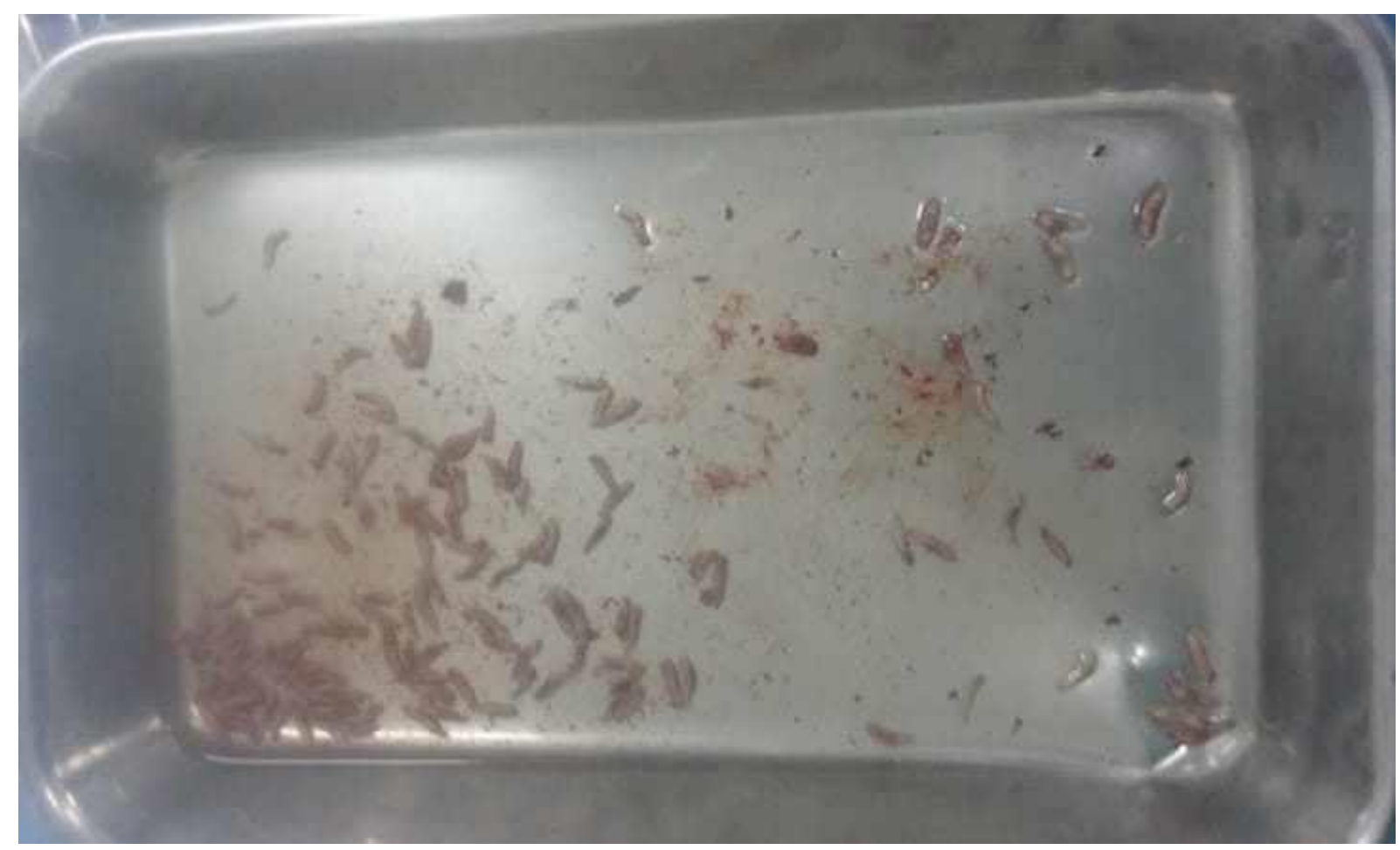

Fuente: Los autores (2020).

El paciente fue hospitalizado y se inició la terapia antibiótica intravenosa Cephalotin 1g, Dipirona y Ketoprofeno, y una sola dosis oral de Ivermectina dos comprimidos, es decir, $12 \mathrm{mg}$ (aproximadamente $200 \mathrm{~g} / \mathrm{kg}$ ), Después de 10 días todas las larvas restantes habían sido erradicadas, sin necesidad de complementar Ivermec.

\section{DISCUSIÓN}

Durante el proceso de desarrollo de larvas, los tejidos adyacentes presentan un proceso inflamatorio, con o sin ulceración o necrosis de tejidos (CARVALHO; SANTOS et al., 2008). Muchas complicaciones graves pueden ocurrir debido a la miiasis: celulitis, erosión de huesos y dientes, bacteriemia y muerte (SZAKACS y MACPHERSON, 2007).

En muchos de los artículos consultados, observamos que los autores mencionan que la miiasis oral es una patología rara, y que los dipteranos no tienen preferencia 
por la edad, el sexo y la etnia. Y que la infestación de la larva de dipterans es más en la zona rural, infestando animales domésticos como perros, gatos, cerdos, bueyes. La opinión general de los autores es que las personas que fueron infestadas por larvas son discapacitados mentales, personas con poco cuerpo e higiene bucal, como bajo nivel de educación, personas de bajo estatus socioeconómico (BOROS; BOROS et al., 2006).

El diagnóstico de miiasis humana es clínico, por lo que uno puede detectar algunas de sus complicaciones puede ser necesario para realizar tomografía computarizada, ultrasonido o resonancia magnética (SHENOUDA; ENTEN et al., 2018).

La presencia de larvas en la piel desencadena una respuesta inflamatoria local con la migración y proliferación de células inflamatorias como neutrófilos, células del mástil, eosinófilos, fibroblastos y células endoteliales. Sin embargo, el recuento completo de células sanguíneas puede mostrar altos niveles de leucocitos y eosinófilos (PAYNE y COSGROVE, 1966) (SHENOUDA; ENTEN et al., 2018).

Algunos autores abogan por un tratamiento convencional de la miiasis, que incluye la eliminación de larvas con la ayuda de sustancias químicas, que tiene como objetivo promover la asfixia de las larvas induciendo su salida de la lesión. En lesiones más grandes donde presenta un cuadro clínico de celulitis adyacente, un desbridamiento de tejidos locales estaría indicado con la eliminación de tejidos necróticos, pero otros defienden como ideal, el tratamiento quirúrgico, que permite la eliminación de todas las larvas aliadas a un desbridamiento, y antibióticos para prevenir la infección secundaria, otro método ya se ha probado como el uso de una dosis única de ivermectina (PARMAR; DAVESSAR et al., 2018).

La miiasis puede considerarse un problema de salud pública que puede prevenirse eliminando los factores de riesgo para la salud humana, como la falta de saneamiento básico y la eliminación inadecuada de la basura, donde se expone material orgánico, que atrae insectos y animales pequeños, creando un ciclo 
sostenible de suciedad. El saneamiento deficiente es probablemente el factor de riesgo más importante para la miiasis humana (FRANCESCONI y LUPI, 2012).

\section{CONCLUSIÓN}

En la literatura, se han propuesto varios tratamientos para la miiasis cavitaria, que van desde la extracción mecánica hasta el uso de sustancias tópicas, orales e intravenosas. Pero un diagnóstico precoz y correcto permite un tratamiento con un pronóstico favorable. Sin embargo, cualquiera que sea el medio empleado, es esencial que el paciente esté orientado a la adopción de medidas de higiene personal adecuadas. Sin embargo, no hay consenso sobre el mejor enfoque terapéutico para los casos de miiasis oral.

\section{REFERENCIAS}

BARNABÉ, A. S. et al. Epidemiologia Da Miíase Cutânea: Revisão Da Literatura. Atas de Ciências da Saúde, São Paulo, v. 4, n. 2, p. 14-22, Abril - Junho 2016.

BOROS, L. F. et al. Mí́ase Labial. Revista Dens, v. 14, n. 1, p. 1-10, Revista Dens, v.14, n.1, maio/outubro 20062006.

CARVALHO, R. W. F. et al. Oral and maxillofacial myiasis associated with epidermoid carcinoma: a case report. Journal of Oral Science, v. 50, n. 1, p. 103-105, 2008.

CAVALCANTI, A. L. Miíase Oral: etiologia, diagnóstico e tratamento. Rev. Fac. Odontol. Porto Alegre, Porto Alegre, v. 49, n. 2, p. 32-35, maio/ago. 2008.

CAVALCANTI, A. L. Miíase Oral: etiologia, diagnóstico e tratamento. Rev. Fac. Odontol. Porto Alegre, Porto Alegre, v. 46, n. 2, p. 32-35, maio/ago. 2008.

FRANCESCONI, ; LUPI,. Myiasis. Clinical Microbiology Reviews , v. 25, n. 1, p. 79 105, Jan. 2012. 
GEALH, W. C. et al. Treatment of oral myiasis caused by Cochliomyia hominivorax: two cases treated with ivermectin. British journal of Oral and Maxillofacial Surgeons, v. 47, n. 1, p. 23-26, January 2009.

GUIMARAES, J. H.; PAPAVERO, ; PRADO, A. P. D. As Mi1ases Na Região Neotropical. Revista Brasileira De Zoologia (Identificação, Biologia, Bibliografia), São Paulo, v. 1, n. 4, p. 239.416, 1983.

KHAN, B. A. et al. Oral and cutaneous myiasis in a 5 year old child from Karachi, Pakistan. Le Infezioni in Medicina, v. 4, p. 385-388, 2018.

MARQUEZ, A. T.; MATTOS, M. D. S.; NASCIMENTO, S. B. Miíases associadas com alguns fatores sócio-econômicos em cinco áreas urbanas do Estado do Rio de Janeiro. Revista da Sociedade Brasileira de Medicina Tropical, v. 40, n. 2, p. 175180, março - abril 2007.

NASCIMENTO, E. M. F. D. et al. Miíases Humanas Por Cochliomyia Hominivorax (Coquerel, 1858) (Diptera, Calliphoridae) Em Hospitais Públicos Na Cidade Do Recife, Pernambuco, Brasil. Entomología y Vectores, v. 12, n. 1, p. 37-51, 2005.

PARMAR, S. et al. Tracheostomal Myiasis: A Case Report And Review Of Literature. International Journal of Scientific Research, v. 7, n. 12, p. 4-6, December 2018.

PAYNE, J. A.; COSGROVE, G. E. Tissue changes following Cuterebra infestation in rodents. The American Midland Naturalist, v. 75, n. 1, p. 205-213, Jan. 1966.

RIBEIRO, F. A. Q. et al. Tratamento da miíase humana cavitária com ivermectina oral. Rev Bras Otorrinolaringol, v. 67, n. 6, p. 755-761, nov./dez. 2001.

SHENOUDA, M. et al. Human Botfly: A Case Report and Overview of Differential Diagnosis. J Investig Med High Impact Case Rep., v. 6, Jan-Dec; 2018.

SILVEIRA, M. A. A. et al. Cavitary myiasis mimicking peritonsilar abscess. Brazilian Journal of Otorhinolaryngology, v. 81, p. 336-338, 2015. 
SZAKACS, T. A.; MACPHERSON,. Nosocomial myiasis in a Canadian intensive care unit. CMAJ, v. 177, n. 7, p. 719-720, 25 September 2007.

TOURÉ, S. M. Les myiases d'importance économique. Rev. sci. tech. Off. int. Epiz., 1994, 13 (4), 1053-1073, v. 13, n. 4, p. 1053-1073, 1994.

VINIT, G. B. ; JAYAVELU, P.; SHRUTHA, S. P. Oral myiasis in a maxillofacial trauma patient. J Pharm Bioallied Sci., v. 5, n. 6, p. 195-197, 5 Jul 2013.

Enviado: Febrero de 2020.

Aprobado: Agosto, 2020. 